\title{
Value of standard radiographs, computed tomography, and magnetic resonance imaging of the lumbar spine in detection of intraoperatively confirmed pedicle screw loosening-a prospective clinical trial
}

\author{
Spirig, José Miguel ; Sutter, Reto ; Götschi, Tobias ; Farshad-Amacker, Nadja A ; Farshad, Mazda
}

\begin{abstract}
BACKGROUND CONTEXT Pedicle screw loosening is common after spinal fusion and can be associated with pseudoarthrosis and pain. With suspicion of screw loosening on standard radiographs, CT is currently considered the advanced imaging modality of choice. MRI with new metal artifact reduction techniques holds potential to be sensitive in detection of screw loosening. The sensitivity and specificity of either of the imaging modalities are yet clear. PURPOSE To evaluate the sensitivity and specificity of three different image modalities (standard radiographs, CT, and MRI) for detection of pedicle screw loosening. STUDY DESIGN/SETTING Cross-sectional diagnostic study. PATIENT SAMPLE Fortyone patients (159 pedicle screws) undergoing revision surgeries after lumbar spinal fusion between August 2014 and April 2017 with preoperative radiographs, CT, and MRI with spinal metal artifact reduction (STIR WARP and TSE high bandwidth sequences). OUTCOME MEASURES Sensitivity and specificity in detection of screw loosening for each imaging modality. METHODS Screw torque force was measured intraoperatively and compared with preoperative screw loosening signs such as peri-screw edema in MRI and peri-screw osteolysis in CT and radiographs. A torque force of less than $60 \mathrm{Ncm}$ was used to define a screw as loosened. RESULTS Sensitivity and specificity in detection of screw loosening was $43.9 \%$ and $92.1 \%$ for MRI, $64.8 \%$ and $96.7 \%$ for $\mathrm{CT}$, and $54.2 \%$ and $83.5 \%$ for standard radiographs, respectively. CONCLUSIONS Despite improvement of MRI with metal artifact reduction MRI technique, CT remains the modality of choice. Even so, CT fails to detect all loosened pedicle screws.
\end{abstract}

DOI: https://doi.org/10.1016/j.spinee.2018.06.345

Posted at the Zurich Open Repository and Archive, University of Zurich ZORA URL: https://doi.org/10.5167/uzh-153668

Journal Article

Accepted Version

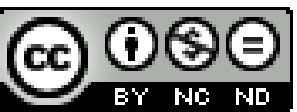

The following work is licensed under a Creative Commons: Attribution-NonCommercial-NoDerivatives 4.0 International (CC BY-NC-ND 4.0) License.

Originally published at:

Spirig, José Miguel; Sutter, Reto; Götschi, Tobias; Farshad-Amacker, Nadja A; Farshad, Mazda (2019). Value of standard radiographs, computed tomography, and magnetic resonance imaging of the lumbar spine in detection of intraoperatively confirmed pedicle screw loosening-a prospective clinical trial. The Spine Journal, 19(3):461-468. 
DOI: https://doi.org/10.1016/j.spinee.2018.06.345 


\section{Accepted Manuscript}

Value of standard radiographs, CT and MRI of the lumbar spine in detection of intraoperatively confirmed pedicle screw loosening - a prospective clinical trial

José Miguel Spirig, Reto Sutter, Tobias Götschi , Nadja A. Farshad-Amacker, Mazda Farshad

PII: S1529-9430(18)30624-7

DOI: 10.1016/j.spinee.2018.06.345

Reference: SPINEE 57725

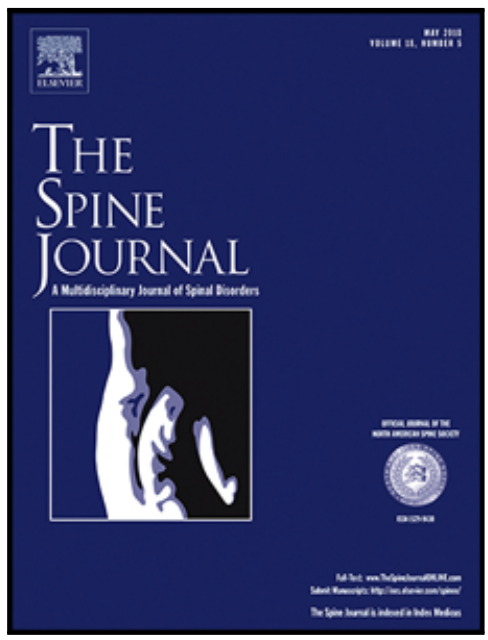

To appear in:

The Spine Journal

Received date: $\quad 19$ February 2018

Revised date: $\quad 18$ June 2018

Accepted date: 19 June 2018

Please cite this article as: José Miguel Spirig, Reto Sutter, Tobias Götschi , Nadja A. Farshad-Amacker, Mazda Farshad, Value of standard radiographs, CT and MRI of the lumbar spine in detection of intraoperatively confirmed pedicle screw loosening - a prospective clinical trial, The Spine Journal (2018), doi: 10.1016/j.spinee.2018.06.345

This is a PDF file of an unedited manuscript that has been accepted for publication. As a service to our customers we are providing this early version of the manuscript. The manuscript will undergo copyediting, typesetting, and review of the resulting proof before it is published in its final form. Please note that during the production process errors may be discovered which could affect the content, and all legal disclaimers that apply to the journal pertain. 


\title{
Value of standard radiographs, CT and MRI of the lumbar spine in detection of intraoperatively confirmed pedicle screw loosening - a prospective clinical trial
}

José Miguel Spirig ${ }^{1}$, Reto Sutter ${ }^{2}$, Tobias Götschi ${ }^{1,3}$, Nadja A. Farshad-Amacker ${ }^{4}$, Mazda Farshad ${ }^{1}$

${ }^{1}$ Spine Division, University Hospital Balgrist Zurich, Zurich, Switzerland

${ }^{2}$ Department of Radiology, University Hospital Balgrist Zurich, Zurich, Switzerland

${ }^{3}$ Institute for Biomechanics, ETH Zurich, Zurich, Switzerland

${ }^{4}$ Institute of Diagnostic and Interventional Radiology, University Hospital of Zurich, Zurich, Switzerland.

${ }^{a}$ Correspondence should be addressed to:

José Miguel Spirig, MD

University Hospital Balgrist, Spine Division, Zürich, Switzerland

Email: jose.spirig@balgrist.ch

Phone number: +41443861111

\begin{abstract}

\section{Background Context}

Pedicle screw loosening is common after spinal fusion and can be associated with pseudoarthrosis and pain. With suspicion of screw loosening on standard radiographs, CT is currently considered the advanced imaging modality of choice. MRI with new metal artifact reduction techniques holds potential to be sensitive in detection of screw loosening. The sensitiyity and specificity of either of the imaging modalities are yet clear.
\end{abstract}

\section{Purpose}

To evaluate the sensitivity and specificity of three different image modalities (standard radiographs, CT and MRI) for detection of pedicle screw loosening.

\section{Study Design/Setting}

Cross-sectional diagnostic study

\section{Patient Sample}

Forty-one patients (159 pedicle screws) undergoing revision surgeries after lumbar spinal fusion between August 2014 and April 2017 with preoperative radiographs, CT and MRI with spinal metal artifact reduction (STIR WARP and TSE high bandwidth sequences). 


\section{Outcome Measures}

Sensitivity and specificity in detection of screw loosening for each imaging modality.

\section{Methods}

Screw torque force was measured intraoperatively and compared with preoperative screw loosening signs such as peri-screw edema in MRI and peri-screw osteolysis in CT and radiographs. A torque force of less than $60 \mathrm{Ncm}$ was used to define a screw as loosened.

\section{Results}

Sensitivity and specificity in detection of screw loosening was $43.9 \%$ and $92.1 \%$ for MRI, $64.8 \%$ and $96.7 \%$ for CT, and $54.2 \%$ and $83.5 \%$ for standard radiographs, respectively.

\section{Conclusions}

Despite improvement of MRI with metal artifact reduction MRItechnique, CT remains the modality of choice. Even so, CT fails to detect all loosened pedicle screws.

\section{INTRODUCTION}

Pedicle screw fixation has become one of the standard methods of instrumentation for spinal fusion. The purpose of pedicle screw fixation is to increase the stability of the segments in order to increase the chance of bony fusion. One common complication is loosening of pedicle screws at the bone interface which, in the presence of pseudarthrosis, often result in revision surgery.

The frequency of screw loosening varies widely throughout the literature. Rates from $1 \%$ to $40 \%$ are reported [1-4] depending on age, bone quality and number of fused levels [5]. However, in most reports, the judgement of screw fixation is based on plain radiograph assessment [6-11]. A radiolucent zone surrounding a pedicle screw can be a sign of screw loosening, but a loose screw is not always surrounded by a radiolucent zone [7]. Also, more than 50\% of radiolucent zones can disappear within 2 years if detected within 6 months after operation [11]. However, radiolucent zones persisting for 2 years or longer after surgery are highly associated with pseudarthrosis [11].

CT, particularly thin-section helical CT [12], is currently considered the diagnostic imaging modality of choice for detection of screw loosening and, potentially, pseudarthrosis, though screw loosening does not always imply pseudarthrosis. Recent studies have investigated the role of SPECT/CT in detecting spinal 
implant loosening with better accuracy though practicality and radiation exposure is a concern $[13,14]$. MRI, with the advantage of avoiding ionizing radiation and better soft tissue visualization [15], is increasingly used in assessment of a patient with spinal disorders. However, concomitant magnetic-susceptibility artifacts seen with metallic implants can hinder images [16,17]. Recent MRI advances and use of non-ferromagnetic titanium implants has improved spinal images with hardware in place [18-21]. In turn, newer MRIs may prove a valuable option in detecting screw loosening.

Recent reports have shown promise using MRI and metal artifact reduction sequences of detection of implant loosening in the knee and hip [22-24]. Studies focusing on pedicle screw loosening are lacking. The aim of this study was to assess the sensitivity and specificity of the most commonly used imaged modalities (standard radiographs, CT, and MRI) in detection of pedicle screws loosening following an attempted posterior lumbar fusion.

\section{MATERIAL AND METHODS}

Ethical approval from the local ethics committee was obtained, and the study was registered at the Swiss National Clinical Trials Portal (registration number: SNCTP000000314).

\section{Study population}

Forty-one patients (22 females, 19 males, mean age 67.3 \pm 10.9 years [range: $27-89$ ]) were enrolled between August 2014 and April 2017 at a single institution with planned revision surgery for painful pseudoarthrosis, adjacent segment disease or proximal junction kyphosis. Further inclusion criteria were informed consent, age older than 18, and titanium instrumentation. The time interval between index surgery and revision surgery was $3.05 \pm 3.12$ years (range: $0.06-13.50$ ).

In total, 159 screws were examined with MRI, CT, and standard radiographs prior to intraoperatively quantifying each screw hold with a torque-measuring device. The time interval between the date of MRI, CT and radiographs and date of revision surgery was $36 \pm 40.7$ days (range: $1-157$ days), $48.7 \pm 58.78$ days (range: 1-304 days) and 29.2 \pm 39.42 (range: 0-188) respectively. 


\section{MRI, CT and radiographic protocol}

All MRI scans were performed at the University Hospital Balgrist on a 1.5-T scanner (Magnetom Avanto, Siemens Healthcare, Erlangen, Germany). The software used was Syngo MR VD13, Siemens Healthcare. The following imaging sequences of lumbar MRI were employed: coronal short tau inversion recovery (STIR) WARP, transverse T2w turbo spin-echo (TSE) high bandwidth, sagittal T2w TSE high bandwidth, sagittal T1w TSE high bandwidth. WARP is defined as high receiver bandwidth of $610-620 \mathrm{~Hz} / \mathrm{px}$ and view-angle tilting (VAT) $100 \%$, and the STIR WARP sequence includes an optimized inversion pulse that adapted to the high receiver bandwidth [25].

All CT scans were performed on a 64-MDCT scanner (Brilliance, Philips Healthcare) using standard "bone" protocol (120 KV; $250 \mathrm{mAs}$ with intensity modulation; $1 \mathrm{~s}$ rotation time; slice collimation, $64 \mathrm{x} 0.625 \mathrm{~mm})$. Image reconstruction produced images with a slice thickness of $2 \mathrm{~mm}$ at a $1 \mathrm{~mm}$ increment. Automatic rigid image registration was performed using the SYNGO multimodality software (Siemens Healthcare, Germany). Conventional lateral and anteroposterior (AP) radiographs were taken at least 6 months before revision surgery.

\section{Image analyses}

All images were assessed separately by two well experienced musculoskeletal radiologists (Reader 1: R.S. senior consultant and Reader 2: N.F. consultant). Analyses of all image sets were performed by commercial Picture Archiving and Communication System (PACS) viewer Merlin 5.2. (Phoenix-PACS, Freiburg, Germany).

The readers independently evaluated MRI, CT, and radiographs without knowledge of the intraoperative findings.

\section{MRI}

Investigated signs of screw loosening in MRI were: presence of peri-screw edema (Reader 1 and 2) and size of peri-screw edema (Reader 2). Maximal width of each sign was recorded irrespective of the length. (Fig. 1) 


\section{CT and radiographs}

Maximum size of peri-screw osteolysis if present, also known as radiolucent zones, was recorded irrespective of the length of the lucency and slice of occurrence in CT. The influence of these signs on screw torque was analyzed separately. (Fig. 2)

\section{Surgical protocol}

All patients underwent revision surgery during which all pedicle screws hold was quantified. After exposing the implants, rods were removed separately, and screw heads were freed from soft tissue. A torque meter (Model TT03, Mark-10 Corporation, New York, USA) with an appropriate screwdriver (Fig. 3) was inserted and the maximum torque was measured while unscrewing the screw. Screws were then replaced, and the subsequent surgery was performed as usual and independent of the study.

\section{Statistical analysis}

All values are given as the mean \pm 1 SD. Interrater reliability was assessed using two-way random effects single measures intra-class correlation (ICC $(2,1))$ for interval-scaled values and Cohens Kappa for nominal variables. Associations between interyal-scaled radiographic predictor variables with screw loosening were investigated using separate ordinary least squares linear regressions including a constant of peri-screw osteolysis and size of edema on natural log-transformed torque values. A p-value $<0.05$ was considered statistically significant. All statistical analyses were performed with SPSS software (version 24.0; SPSS Inc., Chicago, IL, USA).

\section{RESULTS}

\section{Intraoperative Measures}


The overall screw torque force was $144.5 \pm 131.7 \mathrm{Ncm}$ (range: $0-500 \mathrm{Ncm}$ ). Screw loosening was defined as a screw torque $<60 \mathrm{Ncm}$ since the distribution of screw torques seems to contain two overlapping normal

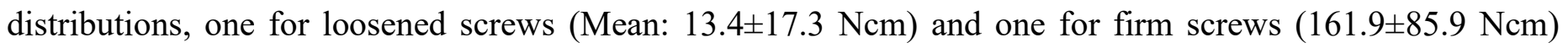
with an intersection point at $60 \mathrm{Ncm}$ (Fig. 4). Fifty-five loosened screws $(<60 \mathrm{Ncm})$ and 104 firm screws $(>60$ Ncm) were identified.

\section{Analysis of peri-screw osteolysis in radiographs}

Linear regression analysis of the radiographic score on ln-transformed (natural logarithm) torque values revealed a significant $(\mathrm{p}<0.001)$ negative association of peri-screw osteolysis with torque (Fig. 5) in the form: Torque $=\mathrm{e}^{5.015-0.574 * \text { RadScore }} . \mathrm{R}^{2}$ was 0.166 . This readout was only done by one reader (reader 1 ) since the role of radiographs in detecting screw loosening has already been previously examined [7].

\section{Analysis of peri-screw osteolysis in CT}

For both readers, linear regression analysis of the radiographic score on ln-transformed torque values revealed a significant $(\mathrm{p}<0.001)$ negative association of peri-screw osteolysis with torque (Fig. 6) in the form: torque $=\mathrm{e}^{4.975-0.553 * \text { RadScore }}($ Reader 1$)$ and torque $=\mathrm{e}^{4.950-0.445 * \text { RadScore }}($ Reader 2$) . \mathrm{R}^{2}$ was 0.229 and 0.240 respectively. Intra-class correlation analysis for detecting radiolucent zones in a CT yielded good agreement of $\mathrm{ICC}=0.860(\mathrm{p}<0,001)$ in a two-way random effects model on a single measures approach.

\section{Analysis of peri-screw bone edema in MRI}

For both readers, presence of bone edema was significantly associated with a lower mean unscrew torque force (Fig. 7). For reader 1 mean unscrew torque without presence of bone edema was $159.45 \pm 132.32 \mathrm{Ncm}$ versus $69.81 \pm 110.49 \mathrm{Ncm}$ with presence of bone edema $(\mathrm{p}=0.001)$. Similar results were measured by reader 2: $177.45 \pm 132.34 \mathrm{Ncm}$ versus $21.78 \pm 23.03 \mathrm{Ncm}$ respectively $(\mathrm{p}<0.001)$.

Cohen's Kappa revealed, however, a poor agreement between the two raters concerning presence of edema around the screw $(\mathrm{k}=0.289, \mathrm{p}<0.001)$. There was agreement for 180 screws and no agreement in 43 screws. 
Linear regression analysis of the radiographic score on ln-transformed torque values revealed a significant ( $p$ $<0.001$ ) negative association of edema size with torque (Fig. 8) in the form: Torque $=\mathrm{e}^{5.144-0.126 * \text { RadScore }}$. $\mathrm{R}^{2}$ was 0.062 .

\section{Sensitivity and Specificity of each radiological modality}

Since there might be no sharp cutoff torque for a loose screw, we also analyzed $80 \mathrm{Ncm}$ and $40 \mathrm{Ncm}$ as a cutoff to test for hypothesis stability. However, this had little effect on sensitivity and specificity in any modality (Table 1).

With a cutoff torque at $60 \mathrm{Ncm}$, the highest sensitivity was achieved by peri-screw osteolysis in CT (52.4\%$64.8 \%)$, followed by peri-screw osteolysis in radiographs $(54.2 \%)$. Sensitivity of MRI $(34.5 \%-43.9 \%)$ was inferior to both, CT and radiographs.

Both readers achieved an excellent specificity using the modality peri-screw osteolysis in CT (97.8\%-100\%), whereas radiographs and MRI achieved lower values (83.5\% and 77.4\%-92.1\%). Overall, peri-screw osteolysis in CT achieved best values with however an unacceptable sensitivity but good specificity $(64.8 \%$ and $96.7 \%$ respectively). (Table 1 )

\section{DISCUSSION}

The aim of this study was to assess the sensitivity and specificity of the most commonly used imaged modalities (standard radiograph, CT, MRI) in detection of pedicle screws loosening within a prospective trial with intraoperative quantification of screw loosening. Our results confirm that peri-screw osteolysis in CT is still the best-indicator for screw-loosening after spinal fusion. However, the maximum sensitivity and specificity was $64.8 \%$ and $96.7 \%$ for CT, $54.2 \%$ and $83.5 \%$ for radiographs and $43.9 \%$ and $92.1 \%$ for MRI respectively.

These results indicate, that none of the modalities are sufficiently sensitive in detecting screw loosening, though CT seems to have reasonable specificity of screw loosening. In other words, if the CT shows periscrew osteolysis, the screw is most likely loose. Sanden et al. reported similar results with $64 \%$ sensitivity and 
$100 \%$ specificity for radiographs using intraoperative screw torque measurement as the gold standard [7]. To the authors' knowledge, there are no prior studies comparing CT with intraoperative torque as a reference. However, CT has been reported to be more sensitive than radiographs for detecting screw loosening [26,27]. Disadvantages of CT are high radiation exposure and its reduced ability to define soft tissues pathologies such as nerve compression, infections, scar tissue, bone edema and intradural pathologies compared to MRI [2831]. Therefore, MRI is often indispensable in the investigation of ongoing symptoms following spinal fusion. To the best knowledge of the authors, this is the first study investigating the role of MRI in detection of screw loosening. Previous studies have shown that postoperative MRI's with metal artifact reduction techniques including high bandwidth optimization, view angle tilting (VAT), multispectral imaging techniques multiacquisition variable resonance image combination (MAVRIC) and slice-encoding for metal artifact correction (SEMAC) may significantly reduce metal-induced artifacts and reliably improve visibility of anatomical structures such as the dural sac, nerve roots and bone-implant interface [25,32]. These techniques require significantly longer acquisition times and may not be feasible on a routine basis [33]. Therefore, we investigated in this study TSE with high bandwidth optimization and STIR WARP sequences which are known to have reasonable acquisition times. However, it remains unknown if sensitivity and specificity of MRI for detecting screw loosening would be improved using sequences with more acquisition time such as SEMAC or MAVRIC [20,22,23,25,34].

The focus of the study question was specifically to define sensitivity and specificity of current imaging modalities such as MRI, CT, and radiographs in detecting screw loosening. Inclusion criteria were therefore not reduced to patients suspected of painful pseudoarthrosis but all kind of indications for revision surgery after spinal fusion. We do not claim to report differentiation of the proportions of patients suffering from isolated pseudoarthrosis versus so-called painful screw loosening. It is, however, evident from a prior study that screw loosening is strongly associated with pseudoarthrosis when still present two years after surgery and that signs of screw loosening are seen in $93.3 \%$ of pseudoarthrosis [11]. Other signs, such as absence of fusion mass or osteolysis and edema around the intervertebral cage, can suggest pseudoarthrosis. These were not analyzed in this study. 
Despite its role in the evaluation of postoperative lumbar fusion patients, MRI has had little role in detecting pseudoarthrosis $[35,36]$. CT has been reported to be the most accurate modality $[15,37]$, though intraoperative detection of pseudoarthrosis remains the gold standard [38,39].

Several other limitations need consideration if interpreting the here presented results. As shown in our study there seems to be no sharp screw torque cut-off that defines a loose screw. We did find an exponential relationship between screw torque and several loosening signs. This contrasts with the study by Sanden et al. [7], which defined $40 \mathrm{Ncm}$ as a cut-off since no extraction torques between 40 and $75 \mathrm{Ncm}$ were found. We could not detect such a clear gap in our data. However, there seemed to be two normal distributions, one of loosened screws and one of clearly firm screws with an intersection point around $60 \mathrm{Ncm}$. We therefore set our cut-off torque at $60 \mathrm{Ncm}$ and compared this with other cut-off torques at $80 \mathrm{Ncm}$ and $40 \mathrm{Ncm}$. Little change in sensitivity and specificity of each image modality was observed with this variation. A further limitation of this study is that only titanium-based implants were included. Since metal artifacts are much more extensive with other materials such as cobalt-chromium or stainless-steel [18,40-42], our results may not applicable to these materials.

Finally, it could be questioned if measurement of unscrew torque is the right parameter to determine screw loosening and whether pullout strength might be more suitable to define screw loosening. Several studies have shown that insertional torque does not necessarily correlate with axial pullout force and both parameters might be influenced by different factors [43-45]. Neither axial pullout force nor unscrew torque seems to adequately mimic physiological loading [44,46-49]. However, in vivo experiments allow only for unscrew torque measurements since both toggling and pullout experiments have a destructive nature that are not ideal for patients. There seems to be, nonetheless, some correlation between screw torque and the number of toggling cycles until failure occurs [44]. As far as the authors are aware, screw torque is the only intraoperative measurable parameter to quantify the screw-bone interface hold for in vivo human studies.

\section{CONCLUSIONS}

$\overline{\text { Standard radiographs, CT, or MRI are highly sensitive in detection of pedicle screw loosening. CT remains }}$ the most specific image modality for screw loosening. 


\section{REFERENCES}

[1] Ohlin A, Karlsson M, Düppe H, Hasserius R, Redlund-Johnell I. Complications after transpedicular stabilization of the spine. A survivorship analysis of 163 cases. Spine (Phila Pa 1976) 1994;19:2774-9.

[2] Sandén B, Olerud C, Petrén-Mallmin M, Larsson S. Hydroxyapatite coating improves fixation of pedicle screws. A clinical study. J Bone Joint Surg Br 2002;84:387-91.

[3] Sandén B, Olerud C, Johansson C, Larsson S. Improved bone-screw interface with hydroxyapatite coating: an in vivo study of loaded pedicle screws in sheep. Spine (Phila Pa 1976) 2001;26:2673-8.

[4] Pihlajämaki H, Myllynen P, Böstman O. Complications of transpedicular lumbosacral fixation for nontraumatic disorders. J Bone Joint Surg Br 1997;79:183-9.

[5] Galbusera F, Volkheimer D, Reitmaier S, Berger-Roscher N, Kienle A, Wilke H-J. Pedicle screw loosening: a clinically relevant complication? Eur Spine J 2015;24:1005-16, doi:10.1007/s00586-0153768-6.

[6] Sandén B, Olerud C, Larsson S, Robinson Y. Insertion torque is not a good predictor of pedicle screw loosening after spinal instrumentation: a prospective study in 8 patients. Patient Saf Surg 2010;4:14. doi:10.1186/1754-9493-4-14.

[7] Sandén B, Olerud C, Petrén-Mallmin M, Johansson C, Larsson S. The significance of radiolucent zones surrounding pedicle screws. Definition of screw loosening in spinal instrumentation. J Bone Joint Surg Br 2004;86:457-61.

[8] Okuyama K, Abe E, Suzuki T, Tamura Y, Chiba M, Sato K. Can insertional torque predict screw loosening and related failures? An in vivo study of pedicle screw fixation augmenting posterior lumbar interbody fusion. Spine (Phila Pa 1976) 2000;25:858-64.

[9] Mizuno K, Shinomiya K, Nakai O, Shindo S, Otani K. Intraoperative insertion torque of lumbar pedicle screw and postoperative radiographic evaluation: short-term observation. J Orthop Sci 2005;10:137-44. doi:10.1007/s00776-004-0873-5.

[10] Ozawa T, Takahashi K, Yamagata M, Ohtori S, Aoki Y, Saito T, et al. Insertional torque of the lumbar pedicle screw during surgery. J Orthop Sci 2005;10:133-6. doi:10.1007/s00776-004-0883-3.

[11] Tokuhashi Y, Matsuzaki H, Oda H, Uei H. Clinical Course and Significance of the Clear Zone Around the Pedicle Screws in the Lumbar Degenerative Disease. Spine (Phila Pa 1976) 2008;33:903-8. doi:10.1097/BRS.0b013e31816b1eff.

[12] Cook SD, Patron LP, Christakis PM, Bailey KJ, Banta C, Glazer PA. Comparison of methods for determining the presence and extent of anterior lumbar interbody fusion. Spine (Phila Pa 1976) 2004;29:1118-23.

[13] Rager O, Schaller K, Payer M, Tchernin D, Ratib O, Tessitore E. SPECT/CT in Differentiation of Pseudarthrosis From Other Causes of Back Pain in Lumbar Spinal Fusion. Clin Nucl Med 2012;37:339-43. doi:10.1097/RLU.0b013e318239248b.

[14] Hudyana H, Maes A, Vandenberghe T, Fidlers L, Sathekge M, Nicolai D, et al. Accuracy of bone SPECT/CT for/identifying hardware loosening in patients who underwent lumbar fusion with pedicle screws. Eur J Nucl Med Mol Imaging 2016;43:349-54. doi:10.1007/s00259-015-3158-7.

[15] Tohtz SW, Rogalla P, Taupitz M, Perka C, Winkler T, Putzier M. Inter- and intraobserver variability in the postoperative evaluation of transpedicular stabilization: computed tomography versus magnetic resonance imaging. Spine J 2010;10:285-90. doi:10.1016/j.spinee.2009.12.020.

[16] Jinkins JR, Van Goethem JWM. The Postsurgical Lumbosacral Spine. Radiol Clin North Am 2001;39:1-29. doi:10.1016/S0033-8389(05)70261-X.

[17] Berquist TH. Imaging of the Postoperative Spine. Radiol Clin North Am 2006;44:407-18. doi:10.1016/j.rcl.2006.01.002.

[18] Koch KM, Hargreaves BA, Pauly KB, Chen W, Gold GE, King KF. Magnetic resonance imaging near metal implants. J Magn Reson Imaging 2010;32. doi:10.1002/jmri.22313.

[19] Viano AM, Gronemeyer SA, Haliloglu M, Hoffer FA. Improved MR imaging for patients with metallic implants. Magn Reson Imaging 2000;18:287-95.

[20] Jungmann PM, Agten CA, Pfirrmann CW, Sutter R. Advances in MRI around metal. J Magn Reson 
Imaging 2017;46:972-91. doi:10.1002/jmri.25708.

[21] Lu W, Pauly KB, Gold GE, Pauly JM, Hargreaves BA. SEMAC: Slice encoding for metal artifact correction in MRI. Magn Reson Med 2009;62:66-76. doi:10.1002/mrm.21967.

[22] Sutter R, Ulbrich EJ, Jellus V, Nittka M, Pfirrmann CWA. Reduction of Metal Artifacts in Patients with Total Hip Arthroplasty with Slice-encoding Metal Artifact Correction and View-Angle Tilting MR Imaging. Radiology 2012;265:204-14. doi:10.1148/radiol.12112408.

[23] Sutter R, Hodek R, Fucentese SF, Nittka M, Pfirrmann CWA. Total Knee Arthroplasty MRI Featuring Slice-Encoding for Metal Artifact Correction: Reduction of Artifacts for STIR and Proton DensityWeighted Sequences. Am J Roentgenol 2013;201:1315-24. doi:10.2214/AJR.13.10531.

[24] Agten CA, Del Grande F, Fucentese SF, Blatter S, Pfirrmann CWA, Sutter R. Unicompartmental knee arthroplasty MRI: impact of slice-encoding for metal artefact correction MRI on image quality, findings and therapy decision. Eur Radiol 2015;25:2184-93. doi:10.1007/s00330-015-3596-4.

[25] Ulbrich EJ, Sutter R, Aguiar RF, Nittka M, Pfirrmann CW. STIR Sequence With Increased Receiver Bandwidth of the Inversion Pulse for Reduction of Metallic Artifacts. Am J Roentgenol 2012;199:W735-42. doi:10.2214/AJR.11.8233.

[26] Ohtori S, Inoue G, Orita S, Yamauchi K, Eguchi Y, Ochiai N, et al. Comparison of teriparatide and bisphosphonate treatment to reduce pedicle screw loosening after lumbar spinal fusion surgery in postmenopausal women with osteoporosis from a bone quality perspective. Spine (Phila Pa 1976) 2013;38:E487-92. doi:10.1097/BRS.0b013e31828826dd.

[27] Abul-Kasim K, Ohlin A. Evaluation of implant loosening following segmental pedicle screw fixation in adolescent idiopathic scoliosis: a 2 year follow-up with low-dose CT. Scoliosis 2014;9:13. doi:10.1186/1748-7161-9-13.

[28] Rausch V, Bannas P, Schoen G, Froelich A, Well L, Regier M, et al. Diagnostic Yield of Multidetector Computed Tomography in Patients with Acute Spondylodiscitis. RöFo - Fortschritte Auf Dem Gebiet Der Röntgenstrahlen Und Der Bildgeb Verfahren 2017;189:339-46. doi:10.1055/s-0043-101864.

[29] van Rijn RM, Wassenaar M, Verhagen AP, Ostelo RWJG, Ginai AZ, de Boer MR, et al. Computed tomography for the diagnosis of lumbar spinal pathology in adult patients with low back pain or sciatica: a diagnostic systematic review. Eur Spine J 2012;21:228-39. doi:10.1007/s00586-011-2012-2.

[30] Notohamiprodjo S, Stahl R, Braunagel M, Kazmierczak PM, Thierfelder KM, Treitl KM, et al. Diagnostic accuracy of contemporary multidetector computed tomography (MDCT) for the detection of lumbar disc herniation. Eur Radiol 2017;27:3443-51. doi:10.1007/s00330-016-4686-7.

[31] Yi JS, Cha JG, Han JK, Kim H-J. Imaging of Herniated Discs of the Cervical Spine: Inter-Modality Differences between 64-Slice Multidetector CT and 1.5-T MRI. Korean J Radiol 2015;16:881. doi:10.3348/kjr.2015.16.4.881.

[32] Song KD, Yoon YC, Park J. Reducing metallic artefacts in post-operative spinal imaging: slice encoding for metal artefact correction with dual-source parallel radiofrequency excitation MRI at 3.0 T. Br J Radiol 2013;86:20120524. doi:10.1259/bjr.20120524.

[33] Hargreaves BA, Chen W, Lu W, Alley MT, Gold GE, Brau ACS, et al. Accelerated slice encoding for metal artifact correction. J Magn Reson Imaging 2010;31:987-96. doi:10.1002/jmri.22112.

[34] Do T, Sutter R, Skornitzke S, Weber M-A. CT and MRI Techniques for Imaging Around Orthopedic Hardware. RöFo - Fortschritte Auf Dem Gebiet Der Röntgenstrahlen Und Der Bildgeb Verfahren 2017. doi:10.1055/s-0043-118127.

[35] Lang P, Chafetz N, Genant HK, Morris JM. Lumbar spinal fusion. Assessment of functional stability with magnetic resonance imaging. Spine (Phila Pa 1976) 1990;15:581-8.

[36] Choudhri TF, Mummaneni P V., Dhall SS, Eck JC, Groff MW, Ghogawala Z, et al. Guideline update for the performance of fusion procedures for degenerative disease of the lumbar spine. Part 4:

Radiographic assessment of fusion status. J Neurosurg Spine 2014;21:23-30. doi:10.3171/2014.4.SPINE14267.

[37] Kosmopoulos V, Schizas C. Pedicle Screw Placement Accuracy. Spine (Phila Pa 1976) 2007;32:E11120. doi:10.1097/01.brs.0000254048.79024.8b.

[38] Quon A, Dodd R, Iagaru A, de Abreu MR, Hennemann S, Alves Neto JM, et al. Initial investigation of ${ }^{18} \mathrm{~F}-\mathrm{NaF}$ PET/CT for identification of vertebral sites amenable to surgical revision after spinal fusion 
surgery. Eur J Nucl Med Mol Imaging 2012;39:1737-44. doi:10.1007/s00259-012-2196-7.

[39] Brans B, Weijers R, Halders S, Wierts R, Peters M, Punt I, et al. Assessment of bone graft incorporation by $18 \mathrm{~F}$-fluoride positron-emission tomography/computed tomography in patients with persisting symptoms after posterior lumbar interbody fusion. EJNMMI Res 2012;2:42.

doi:10.1186/2191-219X-2-42.

[40] Lee M-J, Kim S, Lee S-A, Song H-T, Huh Y-M, Kim D-H, et al. Overcoming artifacts from metallic orthopedic implants at high-field-strength MR imaging and multi-detector CT. Radiographics 2007;27:791-803. doi:10.1148/rg.273065087.

[41] Harris CA, White LM. Metal Artifact Reduction in Musculoskeletal Magnetic Resonance Imaging. Orthop Clin North Am 2006;37:349-59. doi:10.1016/j.ocl.2006.04.001.

[42] White LM, Buckwalter KA. Technical considerations: CT and MR imaging in the postoperative orthopedic patient. Semin Musculoskelet Radiol 2002;6:5-17. doi:10.1055/s-2002-23160.

[43] Kwok AW, Finkelstein JA, Woodside T, Hearn TC, Hu RW. Insertional torque and pull-out strengths of conical and cylindrical pedicle screws in cadaveric bone. Spine (Phila Pa 1976) 1996;21:2429-34.

[44] Zdeblick TA, Kunz DN, Cooke ME, McCabe R. Pedicle screw pullout strength. Correlation with insertional torque. Spine (Phila Pa 1976) 1993;18:1673-6.

[45] Inceoglu S, Ferrara L, McLain RF. Pedicle screw fixation strength: pullout versus insertional torque. Spine J 2004;4:513-8. doi:10.1016/j.spinee.2004.02.006.

[46] Law M, Tencer AF, Anderson PA. Caudo-cephalad loading of pedicle screws: mechanisms of loosening and methods of augmentation. Spine (Phila Pa 1976) 1993;18:2438-43.

[47] Rohlmann A, Graichen F, Weber U, Bergmann G. 2000 Volvo Award winner in biomechanical studies: Monitoring in vivo implant loads with a telemeterized internal spinal fixation device. Spine (Phila Pa 1976) 2000;25:2981-6.

[48] Goel VK, Winterbottom JM, Weinstein JN. A method for the fatigue testing of pedicle screw fixation devices. J Biomech 1994;27:1383-8.

[49] Mehmanparast H, Petit Y, Mac-Thiong J-M. Comparison of Pedicle Screw Loosening Mechanisms and the Effect on Fixation Strength. J Biomech Eng 2015;137:121003. doi:10.1115/1.4031821. 


\section{Figures}

Figure 1:

MRI (Coronal short tau inversion recovery (STIR) WARP) showing the pedicle screw (arrow) and peri-screw edema (arrowheads) as a screw loosening sign.

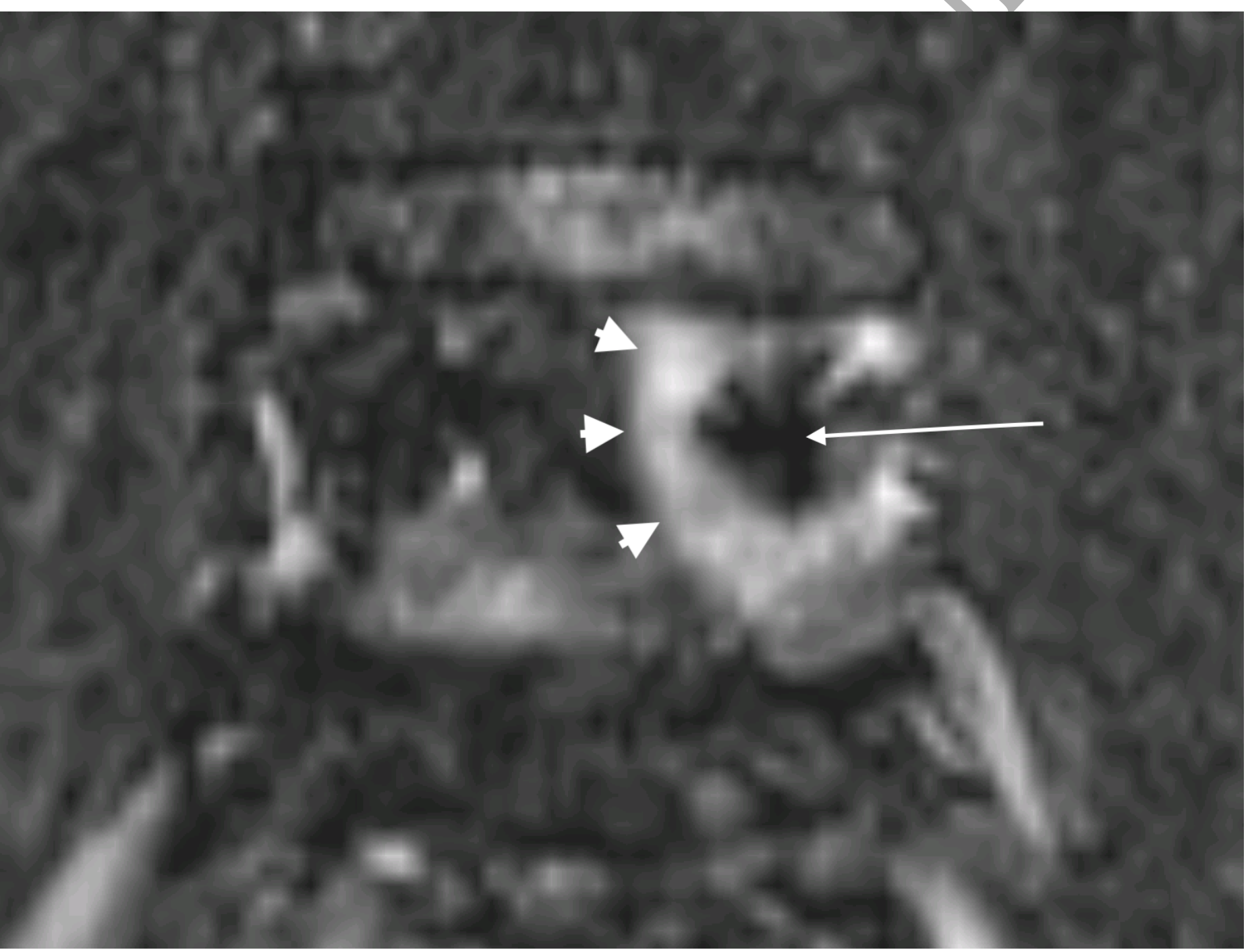


Figure 2:

Transverse CT showing two pedicle screws (arrow) with peri-screw osteolysis (arrowheads) as a screw loosening sign.

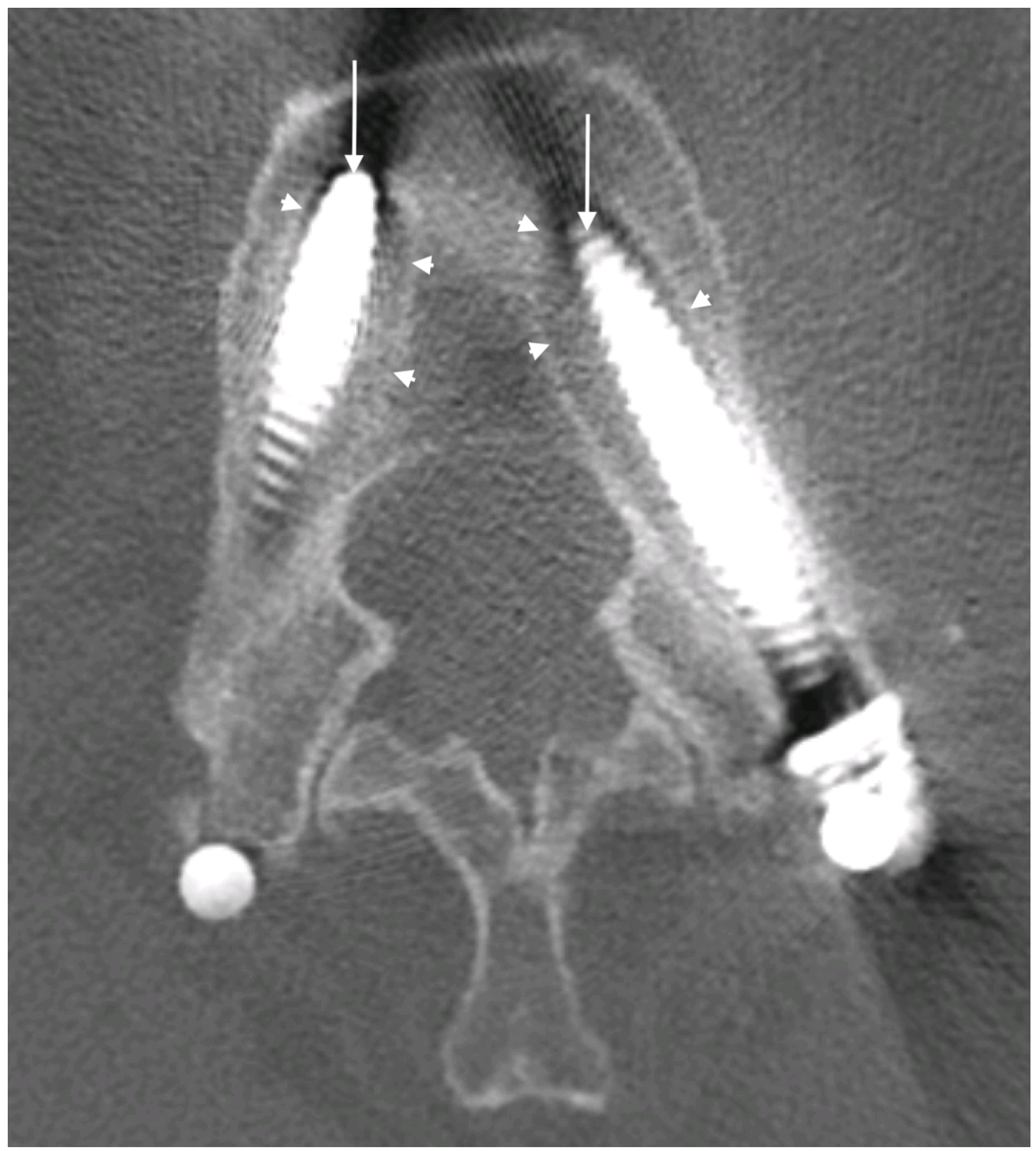


Figure 3:

Torque meter with exchangeable screwdriver for intraoperative screw torque measurement.

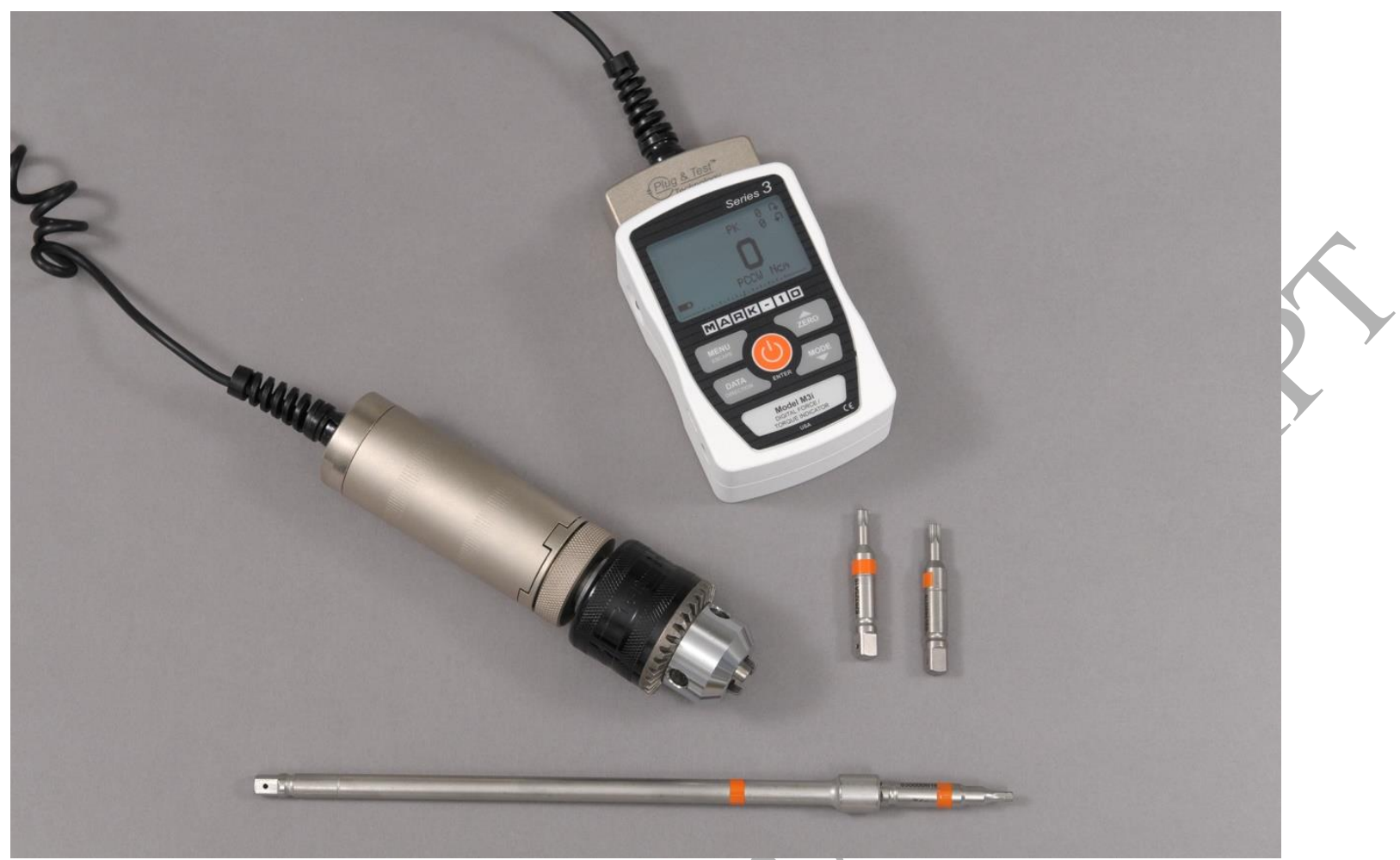


Figure 4:

Distribution of screw torques shows an intersection point of two overlapping normal distributions at $60 \mathrm{Ncm}$. Screw loosening was therefore defined as a screw torque $<60 \mathrm{Ncm}$. However, there might be a transition zone between loosened screw and firm screw shown (grey zone: $60 \mathrm{Ncm} \pm 20 \mathrm{Ncm}$ ).

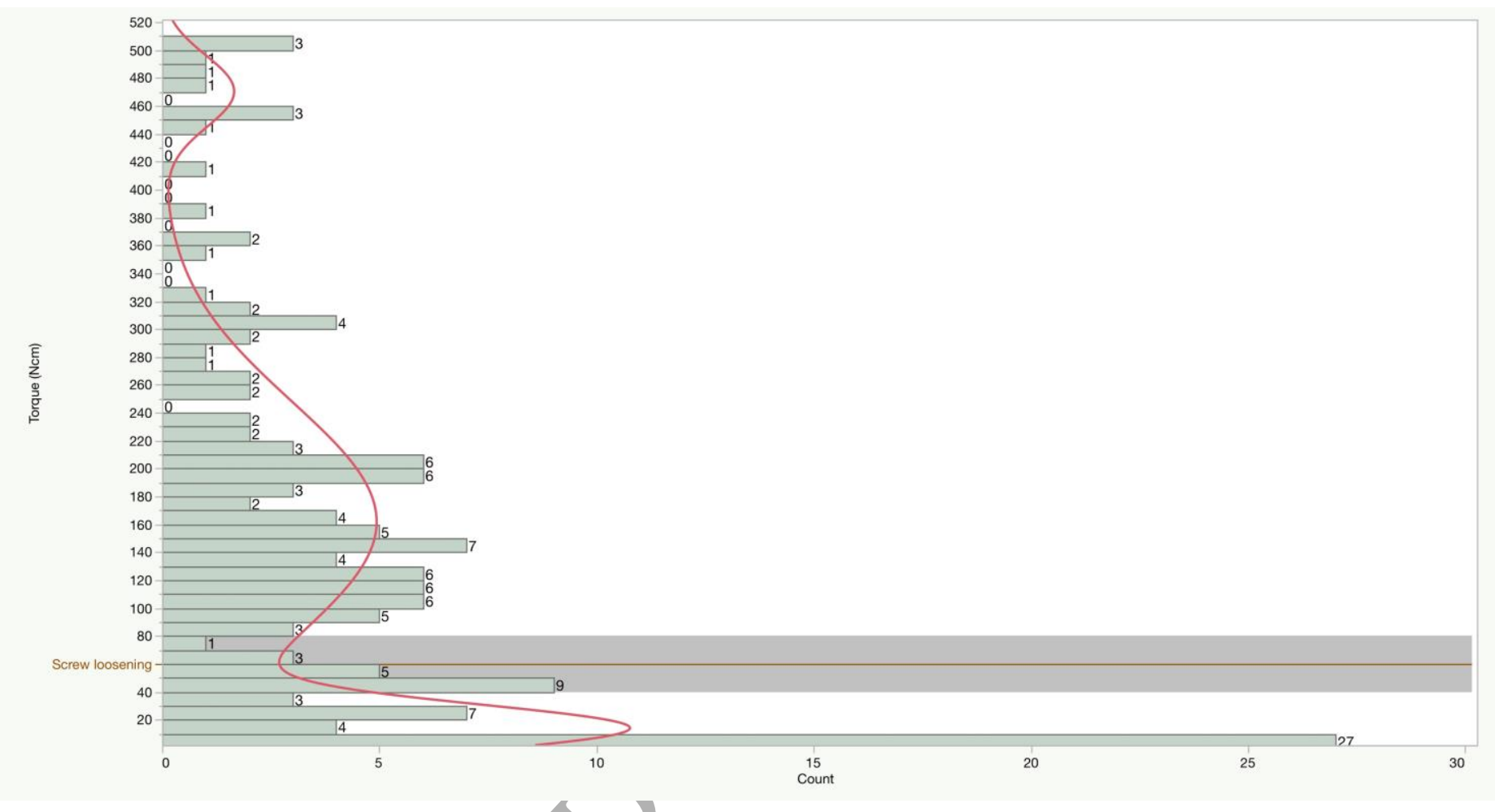

Figure 5:

Linear regression analysis of peri-screw osteolysis in radiographs with ln-transformed torque values shows a significant negative association. 


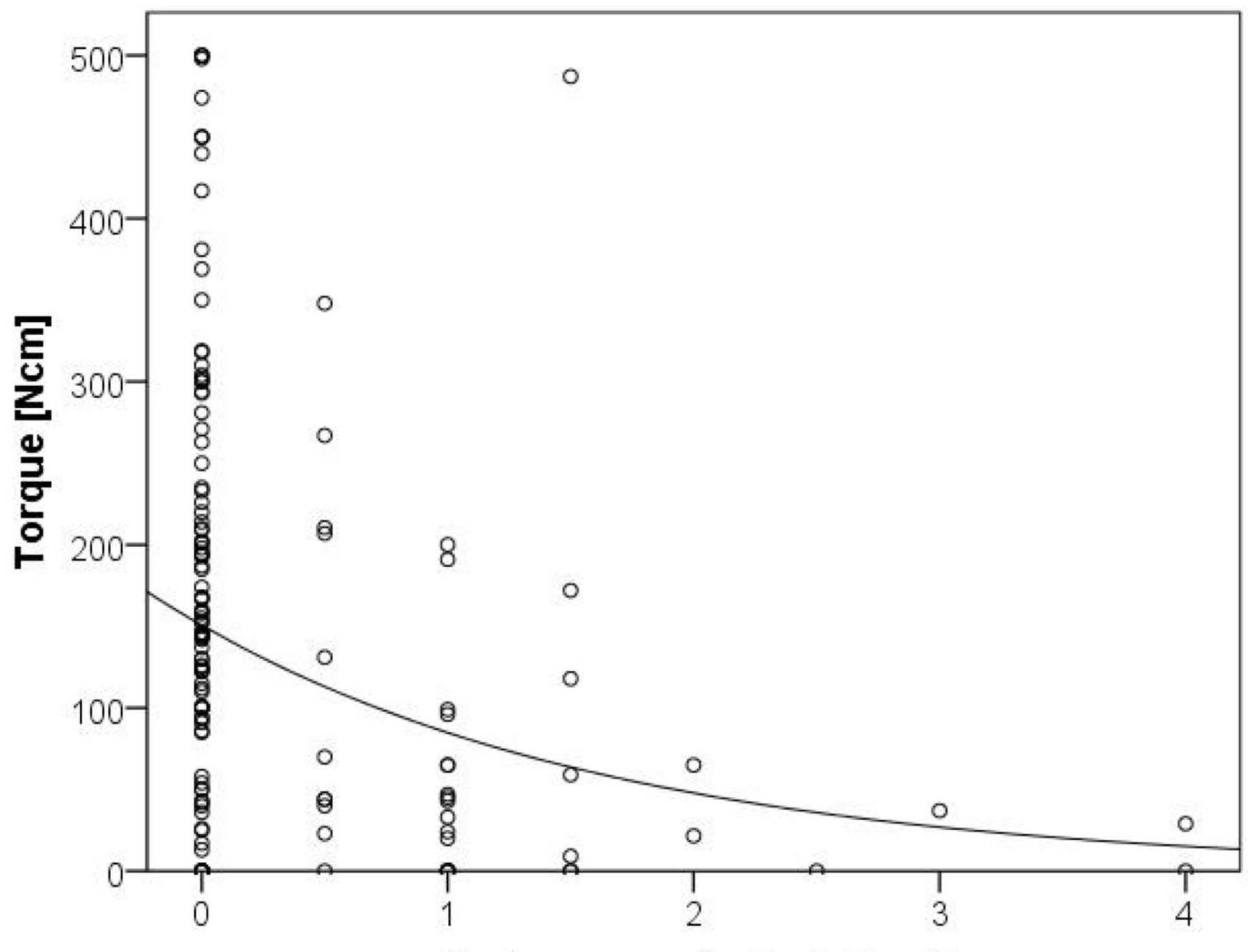

Peri-screw osteolysis [mm] 
Figure 6:

Linear regression analysis of peri-screw osteolysis in CT with ln-transformed torque values. There is a significant negative association in both readers with good interclass correlation.
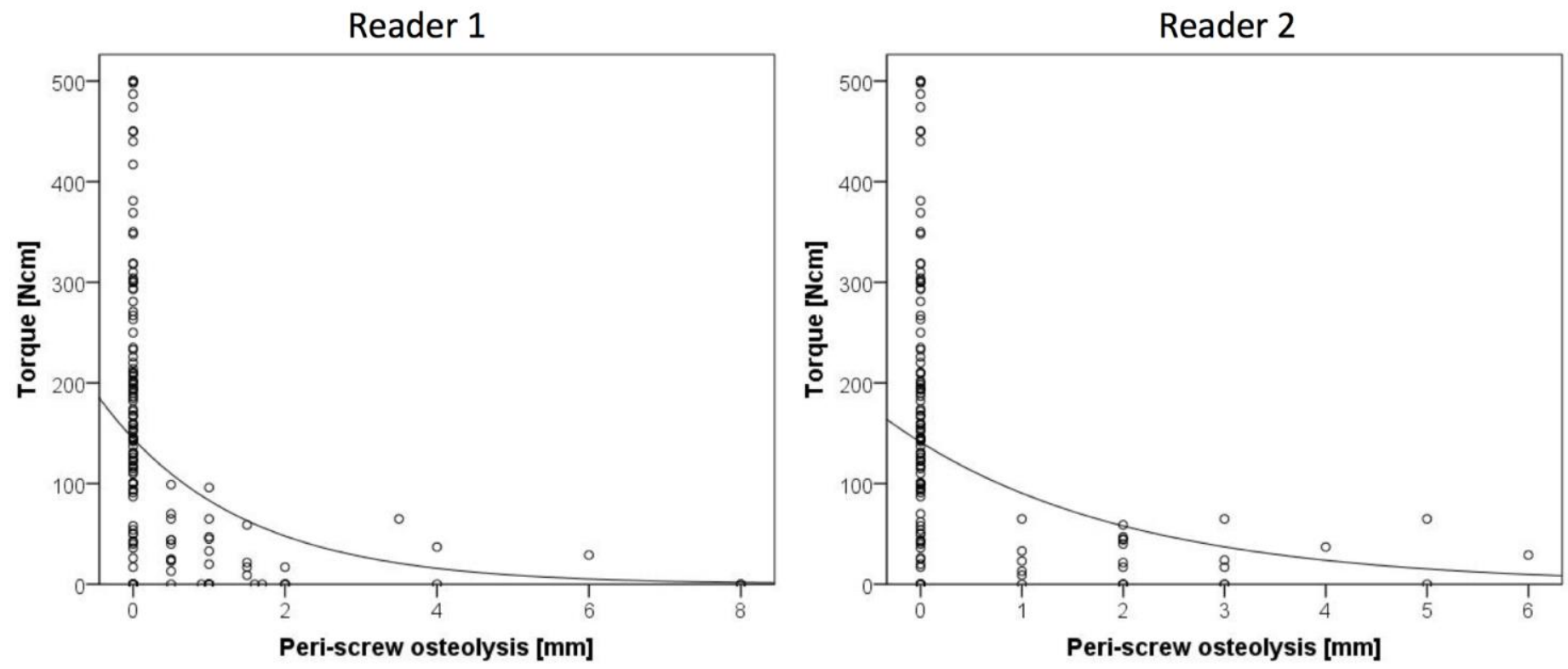

Figure 7:

Mean unscrew torques for both, screws with and without peri-screw edema in MRI. For both readers, there was a significant reduction of unscrew torque in cases with peri-screw edema. 


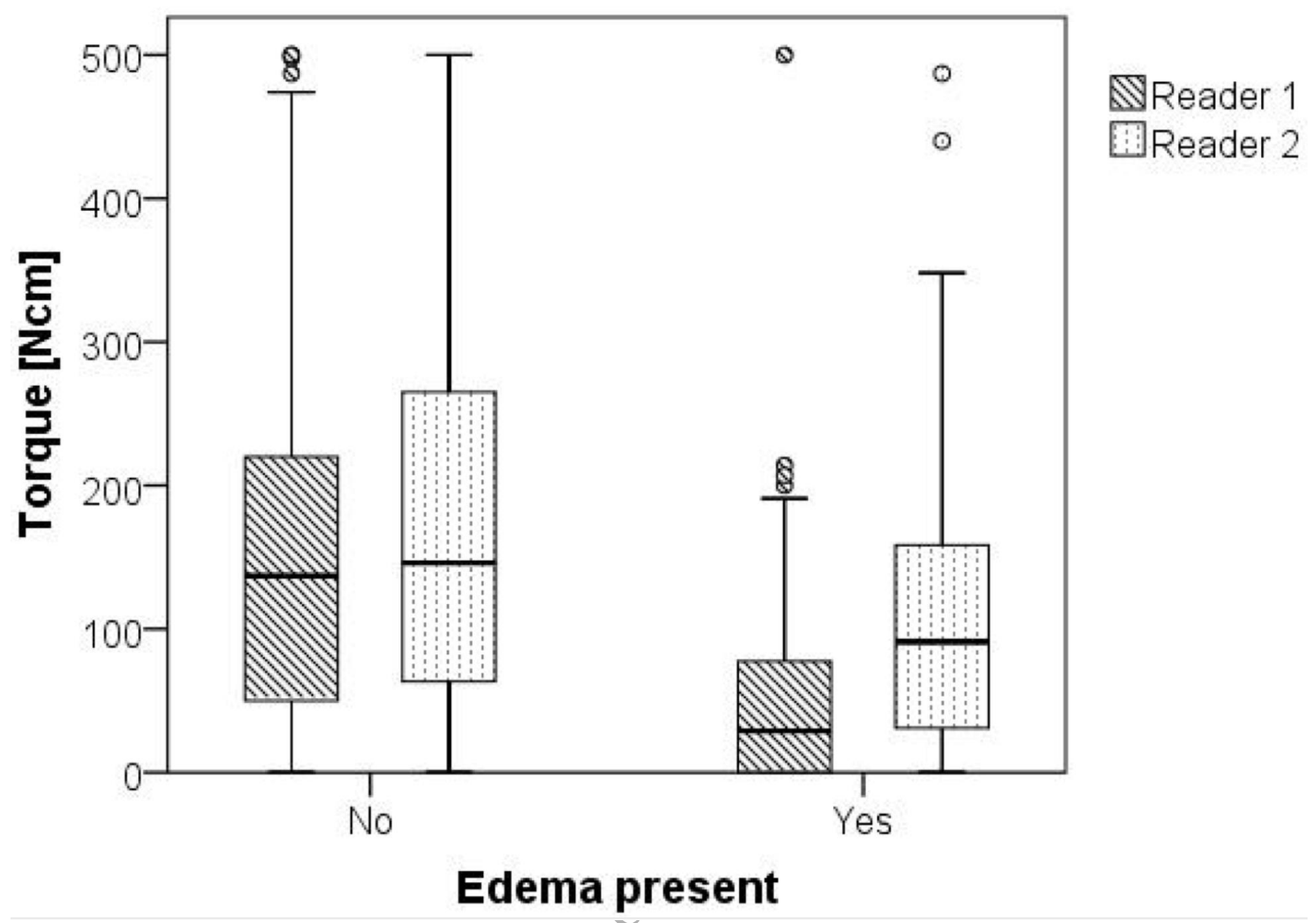

Tables 
Table 1:

Sensitivity and Specificity of different diagnostic modalities with varying definitions of a loose screw $(<40$

$\mathrm{Ncm},<60 \mathrm{Ncm}$ and $<80 \mathrm{Ncm})$

\begin{tabular}{|c|c|c|c|c|c|c|c|c|c|c|c|c|c|}
\hline Predictor & & $\begin{array}{c}\text { Tor } \\
<80 \mathrm{Ncm} \\
\text { Count }\end{array}$ & $\begin{array}{l}\text { que } \\
>80 \mathrm{Ncm} \\
\text { Count }\end{array}$ & Sens. & Spec. & $\begin{array}{c}\text { Torc } \\
<60 \mathrm{Ncm} \\
\text { Count }\end{array}$ & $\begin{array}{l}\text { que } \\
>60 \mathrm{Ncm} \\
\text { Count }\end{array}$ & Sens. & Spec. & \multicolumn{2}{|c|}{$\begin{array}{c}\text { Torque } \\
<40 \mathrm{Ncm}>40 \mathrm{Ncm}\end{array}$} & Sens & Spec \\
\hline \multirow{2}{*}{$\begin{array}{l}\text { Peri-screw osteolysis } \\
\text { radiographs (Reader } 1 \text { ) }\end{array}$} & $\begin{array}{l}\text { No instability } \\
\text { predicted }\end{array}$ & 22 & 81 & \multirow[b]{2}{*}{$57.7 \%$} & \multirow[b]{2}{*}{$87.1 \%$} & 22 & 81 & & & & 87 & \multirow[b]{2}{*}{$55.6 \%$} & \multirow[b]{2}{*}{$79.8 \%$} \\
\hline & $\begin{array}{l}\text { Instability } \\
\text { predicted }\end{array}$ & 30 & 12 & & & 26 & 16 & $54.2 \%$ & $83.5 \%$ & & 22 & & \\
\hline \multirow{2}{*}{$\begin{array}{l}\text { Peri-screw osteolysis } \\
\text { CT (Reader 1) }\end{array}$} & $\begin{array}{l}\text { No instability } \\
\text { predicted }\end{array}$ & 19 & 91 & \multirow[b]{2}{*}{$67.2 \%$} & \multirow[b]{2}{*}{$97.8 \%$} & 19 & 91 & \multirow[b]{2}{*}{$64.8 \%$} & \multirow[b]{2}{*}{$93.8 \%$} & & 97 & \multirow[b]{2}{*}{$69.8 \%$} & \multirow[b]{2}{*}{$89.8 \%$} \\
\hline & $\begin{array}{l}\text { Instability } \\
\text { predicted }\end{array}$ & 39 & 2 & & & 35 & 6 & & & 30 & 11 & & \\
\hline \multirow{2}{*}{$\begin{array}{l}\text { Peri-screw osteolysis } \\
\text { CT (Reader 2) }\end{array}$} & $\begin{array}{l}\text { No instability } \\
\text { predicted }\end{array}$ & 22 & 85 & \multirow[b]{2}{*}{$53.2 \%$} & \multirow[b]{2}{*}{$100.0 \%$} & \multirow[t]{2}{*}{20} & \multirow[t]{2}{*}{87} & \multirow[b]{2}{*}{$52.4 \%$} & \multirow[b]{2}{*}{$96.7 \%$} & 13 & 94 & \multirow[b]{2}{*}{$58.1 \%$} & \multirow[b]{2}{*}{$93.1 \%$} \\
\hline & $\begin{array}{l}\text { Instability } \\
\text { predicted }\end{array}$ & 25 & 0 & & & & & & & 18 & 7 & & \\
\hline \multirow{2}{*}{$\begin{array}{l}\text { Peri-screw edema MRI } \\
\text { (Reader } 1 \text { ) }\end{array}$} & $\begin{array}{l}\text { No instability } \\
\text { predicted }\end{array}$ & 39 & 90 & \multirow[b]{2}{*}{$33.9 \%$} & \multirow[b]{2}{*}{$92.8 \%$} & 36 & 93 & \multirow[b]{2}{*}{$34.5 \%$} & \multirow[b]{2}{*}{$92.1 \%$} & 28 & 101 & \multirow[b]{2}{*}{$34.9 \%$} & \\
\hline & $\begin{array}{l}\text { Instability } \\
\text { predicted }\end{array}$ & 20 & 7 & & & 19 & 8 & & & 15 & 12 & & $89.4 \%$ \\
\hline Peri-screw edema MRI & $\begin{array}{l}\text { No instability } \\
\text { predicted }\end{array}$ & 27 & 68 & & & 23 & 72 & & & 17 & 78 & & \\
\hline (Reader 2) & $\begin{array}{l}\text { Instability } \\
\text { predicted }\end{array}$ & 19 & 20 & $41.3 \%$ & $77.3 \%$ & 18 & 21 & $43.9 \%$ & $77.4 \%$ & 13 & 26 & $43.3 \%$ & $75.0 \%$ \\
\hline
\end{tabular}

